\title{
Novel siderophore, JBIR-16, isolated from Nocardia tenerifensis NBRC 101015
}

\author{
Akira Mukai $^{1}$, Hisayuki Komaki ${ }^{2}$, Motoki Takagi $^{1}$ and Kazuo Shin-ya ${ }^{3}$
}

The Journal of Antibiotics (2009) 62, 601-603; doi:10.1038/ja.2009.84; published online 21 August 2009

Keywords: Nocardia tenerifensis; siderophore; heterobactin; JBIR-16

Nocardia is the causative microorganism of a human infection called nocardiosis. It is also known to produce a variety of compounds with antitumor, $^{1,2}$ antimicrobial ${ }^{3,4}$ and immunosuppressive activity. ${ }^{5,6}$ To take up iron, which is an essential element for all organisms, into cells under iron-deficient conditions, microorganisms produce iron chelators, namely, siderophores. Five types of siderophores have been isolated: hydroxamates, catecholates, salicylates, nitrosophenols and carboxylates. ${ }^{7}$ Some siderophores, such as brasilibactin $\mathrm{A},{ }^{8}$ asterobactin, ${ }^{9}$ nocobactin $\mathrm{NA}^{10}$ and nocardamine, ${ }^{11}$ are produced by Nocardia spp. In the course of our screening program for biologically active compounds of microbial origin, we isolated a novel heterobactin ${ }^{12}$ analog, JBIR-16 (1), containing hydroxamate and catecholate, from the culture broth of Nocardia tenerifensis NBRC 101015 (Figure 1). In this paper, we report the production, isolation, structural determination, and briefly the biological activity of 1 .

The producing strain $N$. tenerifensis NBRC 101015 was cultured on a rotary shaker for 6 days in a 50-ml Erlenmeyer flask containing $10 \mathrm{ml}$ of Brain Heart Infusion broth (Difco Lab., Detroit, MI, USA), including $2 \%$ glucose as a seed culture. The seed culture was transferred into 500-ml Erlenmeyer flasks containing $100 \mathrm{ml}$ of a producing medium consisting of a twice concentrated nutrient broth (Difco Lab.), including $1 \%$ glucose and $1 \%$ glycerol, and incubated on a rotary shaker at 250 r.p.m. for 6 days.

After centrifugation of the culture broth, the supernatant (51) was applied on a HP-20 column (Mitsubishi Chemical, Tokyo, Japan), the column was washed with water and then eluted with $100 \% \mathrm{MeOH}$ to obtain the fraction containing $\mathbf{1}(833 \mathrm{mg})$. The $R_{\mathrm{f}}$ value of 1 showed 0.6 on a TLC analysis using chloroform- $\mathrm{MeOH}(10: 1)$ as mobile phase. The eluate was evaporated to dryness, applied on a normal-phase medium-pressure liquid chromatography column (Purif-Pack SI-60,
Moritex, Tokyo, Japan) and eluted with a chloroform-MeOH gradient $(0-80 \% \mathrm{MeOH})$. The main fraction $(43.8 \mathrm{mg})$ was finally separated by preparative HPLC using an XBridge Prep $\mathrm{C}_{18}$ column $(5 \mu \mathrm{m}$ OBD, 20 i.d. $\times 150 \mathrm{~mm}$, Waters, Milford, MA, USA: mobile phase; $35 \%$

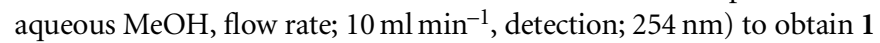
( $3.6 \mathrm{mg}$; retention time $22 \mathrm{~min}$ ).

Compound 1 was obtained as a white powder $\left([\alpha]_{\mathrm{D}}^{25}-9.3, c 0.1\right.$, in $\mathrm{MeOH}, \mathrm{UV}(\mathrm{MeOH}) \lambda_{\max }(\varepsilon) 205$ (50 800), $249 \mathrm{~nm}$ (15085). The IR spectrum of 1 revealed the characteristic absorptions of amide carbonyl $\left(v_{\max } 1643 \mathrm{~cm}^{-1}\right)$ and amide N-H $\left(v_{\max } 1542 \mathrm{~cm}^{-1}\right)$ groups. The HR electron spray ionization-MS of 1 resulted in the $(\mathrm{M}+\mathrm{H})^{+}$ion at $m / z 574.2149$, consistent with a molecular formula of $\mathrm{C}_{26} \mathrm{H}_{32} \mathrm{~N}_{5} \mathrm{O}_{10}$ (calculated for $\mathrm{C}_{26} \mathrm{H}_{32} \mathrm{~N}_{5} \mathrm{O}_{10}, 574.2133$ ).

Although the partial and putative structure of 1 was elucidated by the analyses of a series of NMR techniques, such as constant time heteronuclear multibond correlation ${ }^{13}$ and double-quantum filtered (DQF)-COSY, their connectivities could not be confirmed because of the lack of signals of exchangeable protons. Therefore, the structure of 1 was determined by spectral analyses of a pentamethylated derivative 2, which was prepared by the treatment of 1 with methyl iodide. Compound 2 gave the $(\mathrm{M}+\mathrm{H})^{+}$ion at $\mathrm{m} / z 644$ in the positive mode. In addition, ${ }^{1} \mathrm{H}$ and ${ }^{13} \mathrm{C}$ chemical shifts of these methyl residues (Table 1) indicated the presence of five hydroxyl groups in 2 . The direct $\mathrm{C}-\mathrm{H}$ connectivity was established by heteronuclear single quantum coherence (see Table 1). The analyses of DQF-COSY and heteronuclear multibond correlation spectra of $\mathbf{2}$ established five substructures as follows: In the DQF spectrum, the sequence from methylene proton $1-\mathrm{H}_{2}\left(\delta_{\mathrm{H}} 3.52,3.60\right)$ to an amide proton $4-\mathrm{NH}$ $\left(\delta_{\mathrm{H}} 7.00\right)$ through methylene protons $2-\mathrm{H}_{2}\left(\delta_{\mathrm{H}} 1.95,2.01\right), 3-\mathrm{H}_{2}$ $\left(\delta_{\mathrm{H}} 1.63,2.37\right)$ and an $\alpha$-methine proton $4-\mathrm{H}\left(\delta_{\mathrm{H}} 4.30, \delta_{\mathrm{C}} 51.5\right)$

\footnotetext{
${ }^{1}$ Biomedicinal Information Research Center (BIRC), Japan Biological Informatics Consortium (JBIC), Koto-ku, Tokyo, Japan; ${ }^{2}$ NITE Biological Resource Center (NBRC), National Institute of Technology and Evaluation (NITE), Kisarazu, Chiba, Japan and ${ }^{3}$ Biomedicinal Information Research Center (BIRC), National Institute of Advanced Industrial Science and Technology (AIST), Koto-ku, Tokyo, Japan

Correspondence: Dr M Takagi, Biomedicinal Information Research Center (BIRC), Japan Biological Informatics Consortium (JBIC), 2-42 Aomi, Koto-ku, Tokyo 135-0064, Japan.

E-mail: motoki-takagi@aist.go.jp or Dr K Shin-ya, Biomedicinal Information Research Center (BIRC), National Institute of Advanced Industrial Science and Technology (AIST), 2-42 Aomi, Koto-ku, Tokyo 135-0064, Japan.

E-mail: k-shinya@aist.go.jp
}

Received 9 June 2009; revised 28 July 2009; accepted 30 July 2009; published online 21 August 2009 
a<smiles>O=C(CNC(=O)C(CCCNC(=O)c1cccc(O)c1O)NC(=O)c1cccc(O)c1O)NC1CCCN(O)C1=O</smiles>

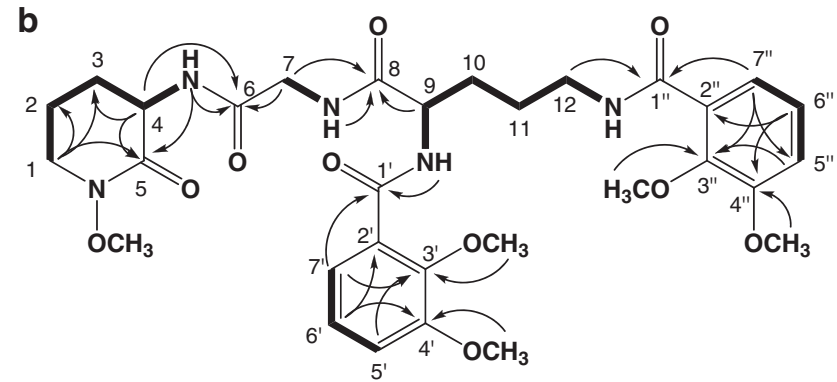

Figure 1 Structure of 1 (a), and ${ }^{1} \mathrm{H}-{ }^{1} \mathrm{H}$ (bold lines) and main ${ }^{1} \mathrm{H}-{ }^{13} \mathrm{C}$ (arrows) correlations in the 2D NMR of 2 (b).

was observed. ${ }^{1} \mathrm{H}-{ }^{13} \mathrm{C}$ long-range couplings in heteronuclear multibond correlation spectrum from $1-\mathrm{H}_{2}$ and $4-\mathrm{H}$ to a carbonyl carbon C-5 $\left(\delta_{\mathrm{C}} 167.1\right)$, together with a ${ }^{13} \mathrm{C}$ chemical shift of C-1 $\left(\delta_{\mathrm{C}} 49.7\right)$, revealed a 3 -amino piperizin-2-one moiety. The proton spin coupling between an amide proton 7- $\mathrm{NH}\left(\delta_{\mathrm{H}} 7.31\right)$ and methylene proton 7- $\mathrm{H}_{2}$ $\left(\delta_{\mathrm{H}} 3.91,4.08\right)$, which in turn ${ }^{1} \mathrm{H}-{ }^{13} \mathrm{C}$ long-range coupled to an amide carbonyl carbon C-6 ( $\left.\delta_{\mathrm{C}} 169.2\right)$, established a glycine residue. The sequence from an amide proton $9-\mathrm{NH}\left(\delta_{\mathrm{H}} 8.66\right)$ to another amide proton $12-\mathrm{NH}\left(\delta_{\mathrm{H}} 8.13\right)$ through an $\alpha$-methine proton $9-\mathrm{H}\left(\delta_{\mathrm{H}} 4.82\right.$, $\left.\delta_{\mathrm{C}} 53.2\right)$, methylene protons $10-\mathrm{H}_{2}\left(\delta_{\mathrm{H}} 1.85,2.06\right), 11-\mathrm{H}_{2}\left(\delta_{\mathrm{H}} 1.77\right)$ and $12-\mathrm{H}_{2}\left(\delta_{\mathrm{H}} 3.40,3.80\right)$, and an ${ }^{1} \mathrm{H}-{ }^{13} \mathrm{C}$ long-range coupling from the $\alpha$-methine proton $9-\mathrm{H}$ to an amide carbonyl carbon $\mathrm{C}-8$ $\left(\delta_{\mathrm{C}} 172.5\right)$, revealed an ornithine moiety. An aromatic proton $5^{\prime}-\mathrm{H}$ $\left(\delta_{\mathrm{H}} 7.03\right)$ was ortho- and meta-coupled to the aromatic protons $6^{\prime}-\mathrm{H}$ $\left(\delta_{\mathrm{H}} 7.13\right)$ and $7^{\prime}-\mathrm{H}\left(\delta_{\mathrm{H}} 7.63\right)$, respectively, supporting the presence of a 1,2,3-trisubstituted benzene ring. In addition, ${ }^{1} \mathrm{H}-{ }^{13} \mathrm{C}$ long-range couplings from the methoxyl protons $3^{\prime}-\mathrm{OCH}_{3}\left(\delta_{\mathrm{H}} 3.90\right)$ and $5^{\prime}-\mathrm{H}$ to an oxygenated aromatic quaternary carbon $\mathrm{C}-3^{\prime}\left(\delta_{\mathrm{C}} 147.7\right)$, from the methoxyl protons $4^{\prime}-\mathrm{OCH}_{3}\left(\delta_{\mathrm{H}} 3.88\right)$ and $6^{\prime}-\mathrm{H}$ to an oxygenated aromatic quaternary carbon $\mathrm{C}-4^{\prime}\left(\delta_{\mathrm{C}} 152.8\right)$, and $7^{\prime}-\mathrm{H}$ to a carbonyl carbon $\mathrm{C}-1^{\prime}\left(\delta_{\mathrm{C}} 166.0\right)$ were observed. These results established a 2,3-dimethoxybenzoate moiety as shown in Figure 1. In the same manner, another 2,3-dimethoxybenzoate moiety was determined.

The connection of these substructures was elucidated by ${ }^{1} \mathrm{H}-{ }^{13} \mathrm{C}$ long-range couplings from 4-NH to C-6, from 7-NH to C-8, from 9-NH to C-1' and from 12-H to C-1" $\left(\delta_{\mathrm{C}} 166.0\right)$, as shown in Figure $1 \mathrm{~b}$. In addition to the molecular formula of 2 , no cross signal was observed with the remaining methoxyl group $1-\mathrm{NOCH}_{3}\left(\delta_{\mathrm{H}} 3.68\right.$, $\delta_{\mathrm{C}}$ 61.3), indicating that this methoxyl group is attached to the nitrogen of the piperidin-2-one moiety. Thus, the structure of $\mathbf{1}$ was established as shown in Figure 1a. A compound related with $\mathbf{1}$ is heterobactin $A,{ }^{12}$ in which one 2,3-dihydrobenzoate moiety in $\mathbf{1}$ is replaced by a benzoxazole residue. In addition, rhodobactin, ${ }^{14}$ which possesses both hydroxamate and biscatecholate moieties, has been
Table $1{ }^{1} \mathrm{H}$ - and ${ }^{13} \mathrm{C}$-NMR data of 1 and 2

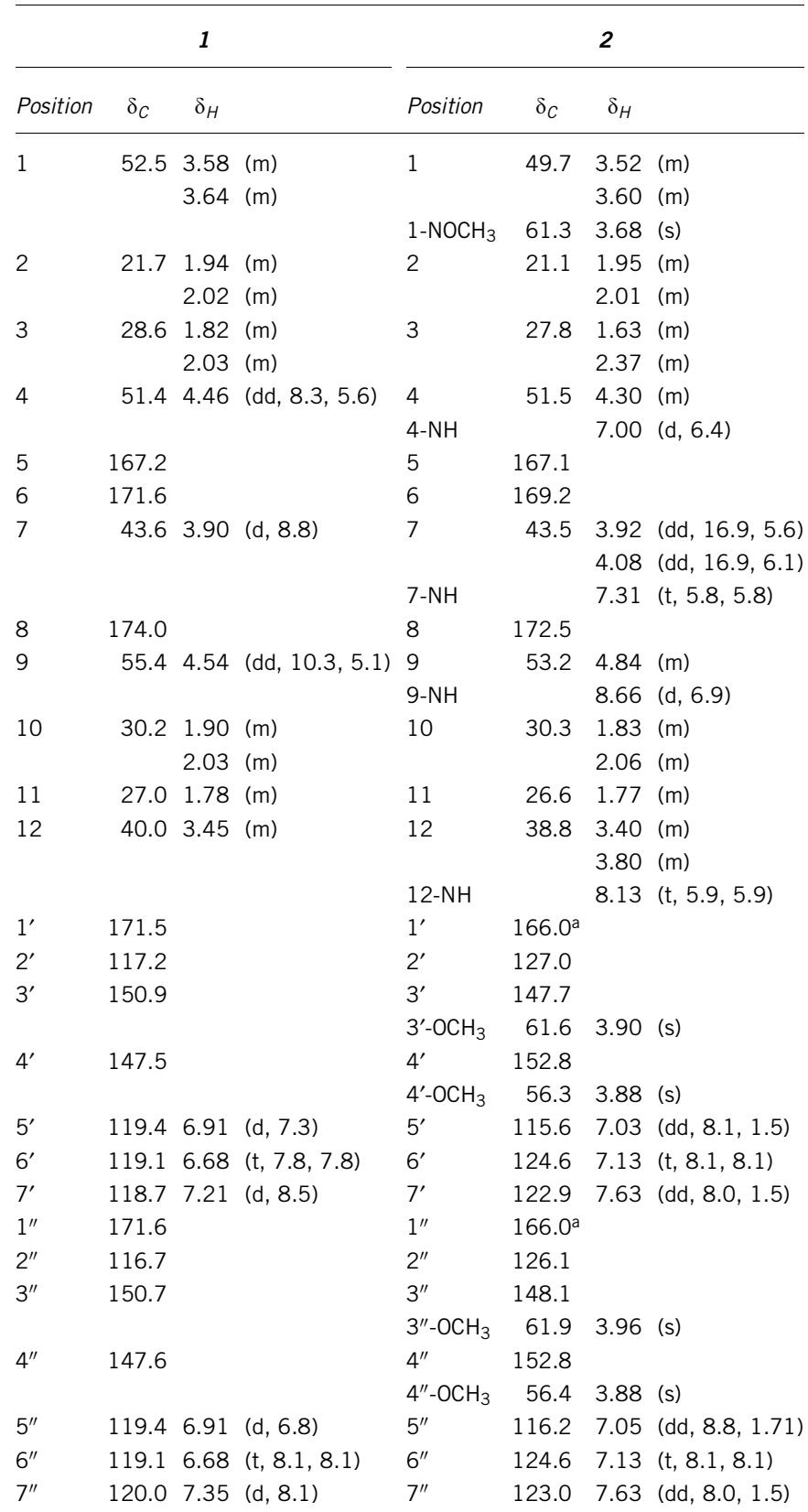

The ${ }^{13} \mathrm{C}(125 \mathrm{~Hz})$ and ${ }^{1} \mathrm{H}(500 \mathrm{~Hz})$ NMR spectra were taken on an NMR system $500 \mathrm{NB} C L$ (Varian, Palo Alto, CA, USA) in $\mathrm{CD}_{3} \mathrm{OD}$, and the solvent peak was used as an internal standard ( $\delta_{\mathrm{C}} 49.0$ p.p.m., $\delta_{\mathrm{H}} 3.30$ p.p.m.).

aThese assignments are exchangeable.

reported as a siderophore. To our knowledge, this is the first report with regard to secondary metabolites from $N$. tenerifensis.

Compound 1 showed a red color in $10 \%$ aqueous $\mathrm{FeCl}_{3}$ and the ESI-MS of the complex resulted in the $(\mathrm{M}+\mathrm{Fe}+\mathrm{H})^{+}$ion at $m / z 627$ in the positive mode. The formation of 1 -iron complex was also confirmed by the changes in UV spectrum (absorption maxima at 205 and $249 \mathrm{~nm}$ were changed to 245 and $364 \mathrm{~nm}$, respectively). However, 2 did not form a complex with ferric ion. The hydroxamate involved in trichostatin A is known to chelate metal ions. ${ }^{15}$ Mycobactin ${ }^{16}$ and exochelin ${ }^{16}$ have been reported as siderophores that lack catechol units. In contrast, azotochelin, ${ }^{17}$ which possesses 2,3-dihydrobenzoate moieties but not hydroxamate functional groups, has 
also been reported to show siderophore activity. Thus, both the hydoxamate and catechol functional groups in $\mathbf{1}$ are considered to have a significant role in chelating properties. The lack of the siderophore activity of 2 , by which hydroxamate and catechols are methylated, also supports the role of these functional groups. Further biological activities are under investigation.

\section{ACKNOWLEDGEMENTS}

This work was supported by a grant from the New Energy and Industrial Technology Department Organization (NEDO) of Japan.

1 Tanaka, Y., Gräfe, U., Yazawa, K., Mikami, Y. \& Ritzau, M. Nocardicyclins A and B: new anthracycline antibiotics produced by Nocardia pseudobrasiliensis. J. Antibiot. 50, 822-827 (1997).

2 Tanaka, Y., Gräfe, U., Yazawa, K. \& Mikami, Y. Production of nocardicyclins by clinical isolates of Nocardia pseudobrasiliensis and in vivo antitumor activity of the antibiotic. J. Antibiot. 5I, 589-591 (1998).

3 Mikami, Y. et al. A new antifungal macrolide component, Brasilicardin B produced by Nocardia brasiliensis. J. Antibiot. 53, 70-74 (2000).

4 Mukai, A. et al. Transvalencin Z, a new antimicrobial compound with salicylic acid residue from Nocardia transvalensis IFM 10065. J. Antibiot. 59, 366-369 (2006).
5 Shigemori, H. et al. Brasilicardin A. A novel tricyclic metabolite with potent immunosuppressive activity from actinomycete Nocardia brasiliensis. J. Org. Chem. 63, 6900-6904 (1998).

6 Mikami, Y. et al. A new antifungal macrolide component, Brasilicardin B produced by Nocardia brasiliensis. J. Antibiot. 53, 70-74 (2000).

7 Drechsel, H. \& Jung, G. Peptide siderophore. J. Peptide Sci. 4, 147-181 (1998).

8 Tsuda, M. et al. Brasilibactin A, a cytotoxic compound from actinomycete Nocardia brasiliensis. J. Nat. Prod. 68, 462-464 (2005).

9 Nemoto, A. et al. Asterobactin, a new siderophore group antibiotic from Nocardia asteroides. J. Antibiot. 55, 593-597 (2002).

10 Ratledge, C. \& Snow, G. A. Isolation and structure of nocobactin NA, a lipid-soluble iron-binding compound from Nocardia asteroides. Biochem. J. 139, 407-413 (1974).

11 DeBoer, C. \& Dietz, A. The description and antibiotic production of Streptomyces hygroscopicus var. Geldanus. J. Antibiot. 29, 1182-1191 (1976).

12 Carran, C. J., Jordan, M., Drechsel, H., Schmid, D. G. \& Winkelmann, G. Heterobactins. A new class of siderophores from Rhodococcus erythropolis IGTS 8 containing both hydroxamate and catecholate donor groups. Biometals 14, 119-125 (2001).

13 Furihata, K. \& Seto, H. Constant time HMBC (CT-HMBC), a new HMBC technique useful for improving separation of cross peaks. Tetrahedron Lett. 39, 7337-7340 (1998).

14 Dhungana, S. et al. Purification and characterization of rhodobactin: a mixed ligand siderophore from Rhodococcus rhodochrous strain OFS. Biometals. 20, 853-867 (2007).

15 Finnin, MS. et al. Structures of a histone deacetylase homologue bound to the TSA and SAHA inhibitors. Nature 401, 188-193 (1999).

16 Ratledge, C. Iron, mycobacteria and tuberculosis. Tuberculosis 84, 110-130 (2004).

17 Corbin, J. L. \& Bulen, W. A. The isolation and identification of 2,3-dihydroxybenzoic acid and 2-N,6-N-di-92,3-dihydroxybenzoyl)-L-lysine formed by iron-deficient Azotobacter vinelandii. Biochemistry 8, 77-762 (1969). 